\title{
Academic use of social networking sites in learners' engagement in underdeveloped countries' schools
}

\author{
Afzal Badshah ${ }^{1}$ (D) . Ateeqa Jalal ${ }^{2}$. Ghani Ur Rehman ${ }^{3}$ (D) . \\ Muhammad Zubair ${ }^{3}$ (D) . Muhammad Muneer Umar ${ }^{4}$ iD
}

Received: 13 April 2021 / Accepted: 2 June 2021 / Published online: 22 June 2021

(C) The Author(s), under exclusive licence to Springer Science+Business Media, LLC, part of Springer Nature 2021

\begin{abstract}
Students' engagement has been a hot topic since the origin of teaching and learning; and is developing rapidly with time and technology. With the recent advances in Information and Communication Technology (e.g, Internet of Things, Artificial Intelligence and 5G), it is a need of the hour to revive its smart use in academia. In underdeveloped countries, parents are offended by financial burdens and educating children is not a priority, resulting students are not effectively engaged in learning. Smartphones are mostly used for fun and entertainment, why not for teaching, learning and monitoring to reshape pedagogy. This study investigated the role of social media in learners' engagement $(1=734)$ by making a productive relationship among the parents $(\mathrm{p}=400)$, teachers $(\mathrm{t}=21)$ and Principal in underdeveloped countries' schools. The results of the study are promising. The statistics for 2018-2019 (i.e, without social media), shows only $3 \%$ to $4 \%$ parental participation in meetings and scarce teachers interest in schooling, resulting in the learner disengagement. However, the statistics from 2019-2020 (i.e, use of social media), shows improvements in the parental engagement up to $20 \%$ and teachers engagement up to $70 \%$, resulting in a productive learners engagement. It is worth mentioning here that the school (located in the village), learner average attendance increased to 95\% (dropped the truancy to almost zero), which got higher authorities admiration.
\end{abstract}

Keywords Social media $\cdot$ Social networking sites $\cdot$ Learners engagement $\cdot$ ICT

\section{Introduction}

Traditional education carries many challenges, learner engagement is the burning one. Particularly, the ongoing pandemic situation of COVID-19 has further enhanced

Ghani Ur Rehman

Ghani.rehman@kkkuk.edu.pk

Extended author information available on the last page of the article. 
this issue. Recent advancements in information and communication technologies (ICT) (eg, ac iot, ac ai and 5G, etc.) have provided hugely smart solutions that address different aspects of life; however, smart solutions are not well integrated into the education system. These smart solution needs to be integrated with education to cope the educational challenges, especially learners engagement (Daud et al. 2017; Aljohani et al. 2019).

Learners engagement is defined as "cognitive involvement, active participation and emotional involvement in any learning content" (Javid et al. 2018). This definition may be extended as that the end result should be productive. In this article, we follow the following definition (Alhazmi et al. 2014).

participation in educationally effective practices, both inside and outside the classroom, which leads to a range of measurable outcomes.

Learner engagement is not the direct goal of the teaching, however, it is an essential reason in learner success. Today, different styles (e.g, Socratic methods (Wikipedia 2020a), Montessori Method (Wikipedia 2020b), warmer, collaboration etc.) are used in classrooms to make students productively engaged (Tanveir et al. 2018). Along with these methods, Information and Communication Technology is taking baby steps to classrooms for learners' engagement. Nevertheless, the use of technology, especially the Social Networking Sites (SNS), have been criticized by many researchers since their discovery, however, in this case, the students do no directly interact with SNS, only teachers and parents use SNS to involve learners (Waterford.org 2020). The teachers and parents communicate for learners development, to boost their outcomes.

The learner engagement is a big issue at each level of learning and it is critically lower especially in the underdeveloped countries' schools. It is also the leading reason of students drop out (Javid et al. 2018). About $50 \%$ learners remain disengaged in classes, resulting their failure and dropout (Brown 2016). Unfortunately, today classrooms (i.e, in the rural and backward areas) are used for knowledge transfer, which need replacement with highly engaged classrooms. For this purpose teachers interest and parents involvements have major impact on learners' engagement likely the employees satisfaction is necessary before the customers' satisfaction. Moreover, the learners' engagement is not limited to learner only; it directly depends on the teachers, parents and institutional productive engagement (shown in Fig. 1). Actually, the learner engagement works in triangle including learner, teacher and parents (Javid et al. 2018). This discussion clearly shows that, instead of working on the learners only, there is need to work on the engagement triangle.

The main contributions of this article are follows:

- Smart engagement of teachers in classrooms in terms of assigning homework to learners and contacting parents for learners productive engagement. Additionally, to send activities pictorial in the parents' group.

- Increasing parents engagement in children schooling in terms of setting their goals and attending the Parent Teacher Meeting (PTM). Furthermore, to monitor their daily activities in parents groups. 


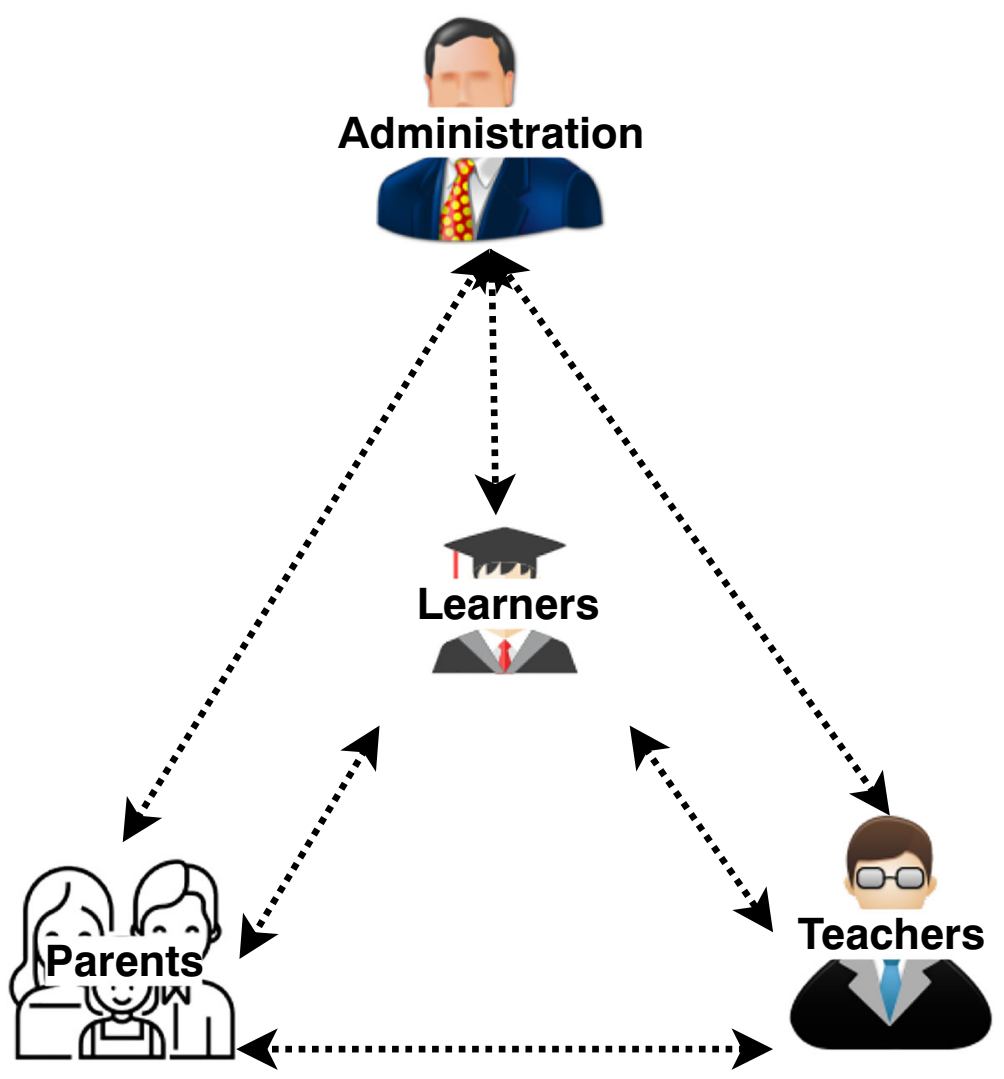

Fig. 1 Proposed engagement structure

- Motivating and productive engagement of learners to do their homework and minimizing truancy. Further contributions are to minimizing the complaints, discipline violation and increasing learner hygiene.

The rest of the article is structured as follows: The Section 2 reviews the related literature; Section 3 explain the research questions; Section 4 discusses the proposed structure; Section 5 evaluates the experimentation; Section 6 analyse the statistics; Section 7 explore the challenges in this study, and finally, the Section 8 concludes the work along with the future directions.

\section{Background and motivation}

Learners' engagement is the most exciting topic and has been arguing since the origin of the teaching and learning. We have investigated this from four perspectives as shown in Fig. 2: parents' perspective, teachers' perspective, technologies 


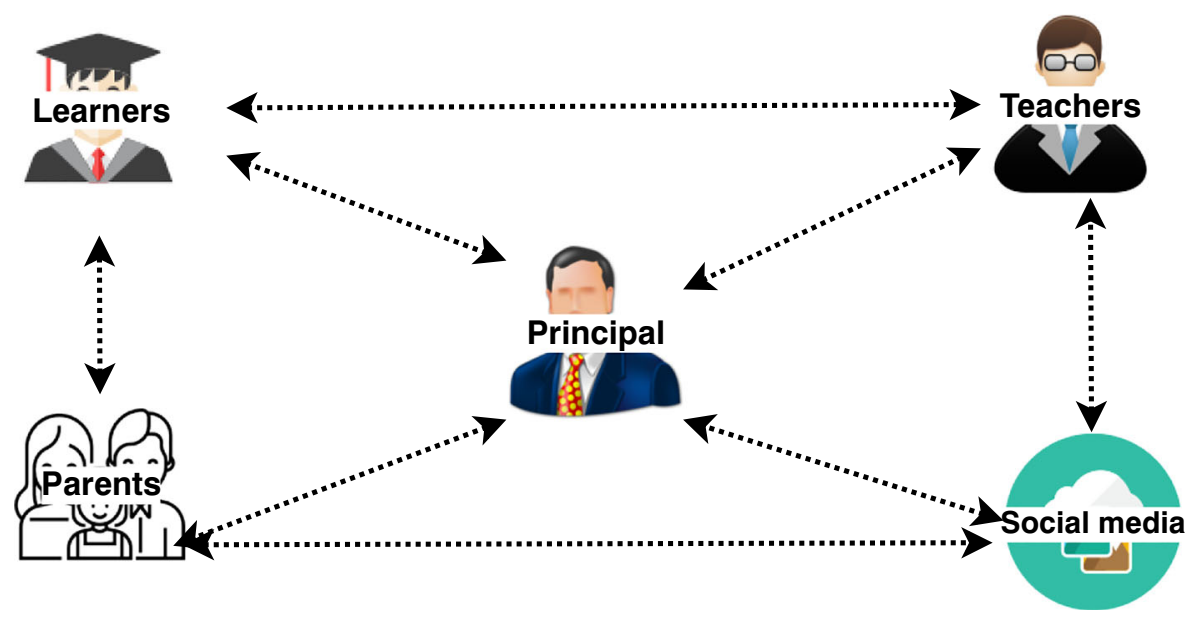

Fig. 2 Use of social media in learners engagement

perspective and as we are using social media for learners engagement, therefore, the fourth perspective is the social media used for learners engagement. The Table 1 shows the symbol used for meetings.

Table 1 Parent-teacher meeting for the academic year 2019-2020 along with calling

\begin{tabular}{|c|c|c|}
\hline Symbol & Month & Description \\
\hline M1 & April 2019 & $\begin{array}{l}\text { April } 2019 \text {, was the first month of the academic year. } \\
\text { Students were verbally instructed by teachers a day } \\
\text { before of meeting, to inform their parents for meeting. }\end{array}$ \\
\hline M2 & May 2019 & $\begin{array}{l}\text { May } 2019 \text {, was the last month before Summer vacations. } \\
\text { Students were verbally instructed by teachers a day } \\
\text { before of meeting, to inform their parents for meeting. } \\
\text { Along with the students, a Facebook post was updated } \\
\text { on the school page for PTM }\end{array}$ \\
\hline M3 & August 2019 & $\begin{array}{l}\text { After Summer vacations, August was the first month. } \\
\text { Vacations post test held at the end of August. Along } \\
\text { with students and Facebook posts, teachers were } \\
\text { instructed to call to the parents for meeting. }\end{array}$ \\
\hline M4 & September 2019 & $\begin{array}{l}\text { In September } 2019 \text {, teachers were instructed to create } \\
\text { WhatsApp group for every class. The teacher added } \\
\text { parents. }\end{array}$ \\
\hline M5 & October 2019 & $\begin{array}{l}\text { In October 2019, Principal of the institution was also } \\
\text { added as the admin of every WhatsApp group for } \\
\text { monitoring purposes. }\end{array}$ \\
\hline M6-9 & November 2019 & $\begin{array}{l}\text { November } 2019 \text {, teachers were instructed to call } \\
\text { those parents who do not participate in the monthly } \\
\text { meeting and this was further continued up to February } \\
2020 \text {. }\end{array}$ \\
\hline
\end{tabular}




\subsection{Parents' perspective}

Parents involvement means the parents' participation in schools events related to their children while parents' engagement is when the parents set their children goals (Waterford.org 2018). Parental involvement increases the student's performance. However, low-income families are seriously lacking this because of their financial crisis. The authors in Dearing et al. (2006), analyzed data from kindergarten to fifth grade on the engagement of their parents. They concluded that the participation of uneducated and low-income parents is very low compared to others, resulting in poor performance of their children. To deeply understand the influence of parental involvement on student life, the authors in Nermeen Nokali et al. (2010) conducted an experimental study in primary school children. Their results suggested that parental involvement has a major impact on children development and progress through school. Chronic absenteeism is the major issue in schools, and teachers consider it as the main reason for learners failure. Authors in Sheldon and Epstein (2010), involve the parents, teachers and community to reduce it. They concluded that positive communication with parents and community minimizes the absenteeism.

Similarly, authors in Goossens et al. (2012), explored the different aspect of parental involvement and their role in students motivation and engagement. They conclude that strong communication and relationship among parents, children, schools, and communities plays a good role in students motivation and engagement. Parental involvement was further explored by Many other studies, Hill and Tyson (2009) and Sheldon and Jung (2015), and Waterford.org (2019), deeply discussed the roles of parents in learners' engagement.

\subsection{Teachers' perspective}

Teachers have the most powerful influence on learners. The school children take the teacher as their heroes. Authors in Tanveer et al. (2012), investigated the teacher influence on learner motivation and proposed various methods to keep the learner motivated in classes. Author in Davion (2017), further reviewed the literature on learner motivation and engagement and concluded that teachers play a big role in learner engagement.

Quin in Daniel (2017), discussed the Teacher-Student-Relationship (TSR). They analyzed 46 studies and concluded that TSR is fully associated with school management. Moreover, their conclusion indicates that TSR increases student engagement. Authors in Zhe and Ken (2018), experimented with the relationship of parents and teacher at middle-level students. During the assessment, they observed positive feedbacks. Students showed positive results than the previous assessments. Authors in Kangas et al. (2017), explored the students' satisfaction and teachers' engagement in play full learning environment. They used digital technologies for 331 students and 15 teachers to keep them engaged. They carried out the students' satisfaction survey and assess them for their learning. The result shows great improvement in students' behavior and engagement. Similarly, authors in Diaz et al. (2017), experiment the same with kinder garden students and found a fruit full results. 


\subsection{Use of technology}

In traditional classrooms, energizers and warmers are used to mobilize learners for learning. Games make active (i.e, physically and mentally) the learners for class. Authors in Ruiperez-Valiente et al. (2020) extended the same idea by introducing the Learner Engagement Technology (LET) based smart campuses. They used Game Based Learning (GBL) and found promising results. The same was advanced by Xuesong et al. (2018), by developing games for classrooms. They proposed an exciting multidimensional game to involve students in different ways.

The advanced smart devices (e.g, accelerometer, gyroscope, and magnetic sensor) helps in learner engagement in classes. Lu et al. (2019), investigated the same gap and proposed a smart system to monitor the learners' engagement in different activities (e.g, writing notes or raising the hand in class). In results, they concluded that the system accurately monitored and reported the learner activities. According to these reports, students were engaged. Authors in Kljun et al. (2014) proposed a persuasive technology used to trigger the learners' engagement in mobile and e-learning. The results show that using adaptive triggering in mobile learning increases learners engagement and course conversion rate more than just regular triggering.

\subsection{Use of social media}

Motivation is the driving force, which drives the learner towards productive engagement. Author in Marzo et al. (2017), used a social media database and personalized learning for learners intrinsic motivations. They observed that the students using social media were more motivated than the others. Authors in Popescu and Leon (2018) used social media for the student's engagement prediction. They observed the student's social media account for their involvement in studies. Observation shows that students using social media were more involved than others. Authors in Ahmed et al. (2018), investigated the effect of social media on students. Their study included 1300 schools students and observed that the social media positively motivated them towards learning. Authors in Laserna and Miguel (2018), conducted the similar experiment on linguistics classes and fined the similar results.

To strength the structure of elearning program, authors in Zankadi et al. (2018), proposed hybrid system of facebook and MOOC. Experimentation shows a positive impact on teaching and learning. Many other authors, such as Silius et al. (2013), Khan and Chiang (2014), and Mbogho (2017) and Whitehill et al. (2014) explored the use of social media in education.

\section{Theoretical framework}

This study deals with a underdeveloped countries schools, where parents are engaged with economic crisis and the child's education is not their first priority. Children education is not given a preferences and parents do not visit the schools or ask the teachers for child progress. As a result, students are not involved in learning, causing the entire educational system to disintegrate. 
Parenting and teaching is the most difficult and complex job to do, however, in the underdeveloped countries, it is not ever taken seriously. Therefore, the objective of this study is to use the Information and Communication Technology and SNS in the underdeveloped countries schools to engage the learners in the class through teachers, parents and institutional assistance. Due to lower-income, parents cannot spare time to have personal communication with teachers, therefore, technology-based communication is introduced to be in contact with them.

The effective use of SNS is a productive platform for E-learning and engaging the teachers, parents and learners. Here in this study, SNS are used to make a strong relationship among the parents, teachers and Principals, resulting learners' productive engagement.

We investigated the learners engagement in three perspective, as shown in Fig. 1: (i) parents perspective, (ii) teachers perspective and (iii) administration perspectives.

Parents involvement is when parents and teachers share the responsibility to help the student to achieve their educational goals. Parents involvement occurs when teachers involve parents in school meetings and other related events. Parents also provide support at home or at school (Waterford.org 2020; The National PTA 2000). Total 400 parents took part in this study. It is internationally known truth that, schools are as better as their teachers. A teacher is the key factor in learners' motivation and develop learners and play a big part in their success. Student get more influence from teachers than parents (Tanveer et al. 2012). A teacher's passion is an important factor in student motivation. If a teacher is passionate, so are the learners. A loving teacher stems from confidence, excitement, and love of the subject. Total 21 teachers (15 regular and 6 volunteers) took part in this study. Administration of the school makes policies for the school, which are followed by parents, teachers and students. The friendly and attractive rules motivate everyone otherwise, the institutions go down (Badshah et al. 2019). To connect these stack holders, social media provides a great platform. As schools' learners, social media may not be recommended for learners, however, the parents, teachers and head of the institutions use it to keep the student productively engaged (Ibanez et al. 2014).

This study investigate the following questions;

- What is the SNS role in smart engagement of teachers in classrooms in terms of assigning homework to learners and contacting parents for learners productive engagement?

- What is the SNS role in parents engagement in children schooling in terms of setting their goals and attending the PTM?

- What is the SNS role in motivating and productive engagement of learners to do their homework and minimizing truancy?

- What is the SNS role to minimize the complaints and discipline violation?

\section{Research design}

During the 10 years of careful observation of the educational process of certain institutions, it is noted that lack of parental involvement leads to student disengagement 
that is the main cause of early school leaving. For this study, the 2019-2020 academic year is decided for observation and analysis on behalf of the 2018-2019 reports. The record for the academic year 2018-2019 shows that only $1 \%$ to $2 \%$ of parents attended the school meeting, despite of a request at each meeting.

The study was conducted on learners $(l=734)$, parents $(p=400)$ and teachers $(t=20)$ at Government Boys High School Chapri, (District Mianwali, Punjab, Pakistan). School is from kindergarten to secondary level having 21 teacher (regular $=14$, volunteer $=6$ ). The 60 percent parents were government employees (lower scale) and 40 percent were labor. The income of the parents ranges from 10,000 to 45,000 per month and on average this was only 15000 per month.

Institutional factors refer to an institution's services, policies and practices to support learners' engagement. In our case, the institution sets policies to facilitate learners' engagement through parents and teachers. During the academic year 20192020 admission process, the visit of the parents was necessary (before this learners were promoted without meeting the parents). It was necessary to provide the WhatsApp number (it could be from other relatives). SNS users were also invited to like the school's Facebook page.

The first challenge, which was faced that about 50 percent guardian did not have a smart phones in their homes. Therefore, parents were requested to give anyone contact who were in relative and s/he may give a child report at learner home. Finally, 60 percent guardian/parents register their WhatsApp contacts.

After completing the learners' registration, the new session started and the monthly test was scheduled at the end of each month. Every month PTM was scheduled on the first week . To help parents effectively, primary students' parents were attended at the primary portion. A teacher along with a supporting staff member was deployed to help parents and guide them about the learners' monthly progress report. Parents of middle and secondary level learners were entertained separately with the assigned staff.

The study was conducted on two scenario, the traditional scenario without use of social media and use of social media scenario.

\subsection{Traditional scenario without use of social media}

The analysis for the 2018-2019 academic year is included in this scenario. The first 3 months of the 2019-2020 academic year took place according to the traditional scenario. The matrices for each month are as follows.

April 2019 was the first month of the academic session. The first week was all about registration of students and meeting parents. At the end of the month, after passing the monthly examination, the learners received verbal instructions from the teachers (i.e, one day before the meeting) to inform their parents about the PTM. Summer vacation begins in early June in most of Pakistan, therefore, May 2019 was the last month before the vacations. Students were given oral instructions from teachers the day before the meeting to notify their parents of a PTM.

Historically, parents have not been participating in the monthly meeting and the maximum participation did not cross the 5\%. Table 2 shows the detail of parents attending meeting in academic year 2018-2019. In the table the At shows the parents 
Table 2 Parents engagement for the academic year 2018-2019

\begin{tabular}{lll}
\hline Meeting & At & att \\
\hline April 2018 & 10 & 7 \\
May 2018 & 4 & 8 \\
August 2018 & 5 & 10 \\
September 2018 & 15 & 10 \\
October 2018 & 8 & 7 \\
November 2018 & 5 & 9 \\
December 2018 & 30 & 35 \\
January 2019 & 5 & 8 \\
February 2019 & 9 & 12 \\
\hline
\end{tabular}

who attended the meeting during the meeting days and Att shows those parents who visited in normal days other than the specified PTM day.

\subsection{Use of social media scenario}

Facebook is actively used in the village around the age of 18 to 40 years. Therefore, for convenience, the Facebook page was selected for communication.

August was the first month after the summer vacation. The post-vacation test was conducted at the end of August. Along with students and Facebook posts, teachers were instructed to call the parents for meeting. Here we concluded that it is absolutely not possible to communicate with parents on one Facebook page for 734 learners. Therefore, it was decided to create WhatsApp groups for every section to minimize the communication delay.

In September 2019, teachers were asked to create a WhatsApp group for each class section. The teacher added all the parents in the class and a message was broadcasted to the parents. In October 2019, the Principal of the institution was also added as an administrator of each WhatsApp group for monitoring purposes.

In November and the following months, teachers' communication with parents was monitored. At the same time, homework and learners' participation were also monitored. The same process was performed and followed for the next four months. Parental involvement was monitored for parents attending the monthly meeting and asking teachers in WhatsApp groups; teachers were monitored for the frequency of homework and the frequency of homework marked; likewise, the learners were followed for homework, attendance, monthly results and discipline.

\section{Evaluation}

Evaluation of this experiment is divided into two sections. The first section calculation refer the first scenario (i.e, traditional way of engaging teachers, parents and learners) and the second section represents scenario 2 (i.e, using social media for engaging). The analysis was monitored for three perspective: parents perspective, teachers perspective and learners perspective. 


\subsection{Population}

This experiment was carried out on the learners, teachers and parents of Government High School Chapri, District Mianwali (Punjab, Pakistan). For the academic year 2019-20. The total learners' enrollment was 734; total teachers strength for primary, middle and secondary was 10,7 , and 4 respectively. The parents who were contacted for 734 students were 400 . The gender ratio was $100 \%$ male because (due to cultural and Government policies), males and females have separate schools.

\subsection{Evaluation methodology and results}

As discussed earlier, this study evaluation methodology is categorized into three classes: (i) parents' perspective, (ii) teachers' perspective and (iii) learners' perspective.

\subsubsection{Teachers' perspective}

This section answers the RQ-1, SNS role in smart engagement of teachers in classrooms in terms of assigning homework and contacting parents for learners productive engagement. Teachers have a very important position in schooling. It is a universal truth that the "schools are as good as the teachers". Before engaging learners, it is essential to engage the teachers productively. It is observed that those classes have better performance (in terms of behavior, motivation and cognitive), whose teachers involved parents in their children schooling (Waterford.org 2020) (Table 3 and Fig. 3 shows the results). The values of calculation are shown in average. In this experiment, teachers were monitored for a frequency of homework given to learners $(\eta)$, average monthly contact with the parents $(\epsilon)$, frequency for which the homework was marked $\delta$, percentage of calls teachers made to parents $(C P)$.

April has a very low turnout as shown in Table 4. It was the admission month and teachers were busy with the admission. The direct contact with parents and after adding Principal to the WhatsApp group increases their efforts in assigning and marking the homework. The frequency of giving homework to the learners rise for each

Table 3 Teachers' engagement for academic year 2019-2020

\begin{tabular}{llll}
\hline Symbol & $\eta$ & $\epsilon$ & CP\% \\
\hline M1 & 14 & 6 & 95 \\
M2 & 18 & 8 & 20 \\
M3 & 20 & 12 & 20 \\
M4 & 18 & 18 & 25 \\
M5 & 22 & 19 & 30 \\
M6 & 22 & 20 & 80 \\
M7 & 23 & 23 & 80 \\
M8 & 14 & 24 & 80 \\
M9 & 18 & 18 & 80 \\
\hline
\end{tabular}




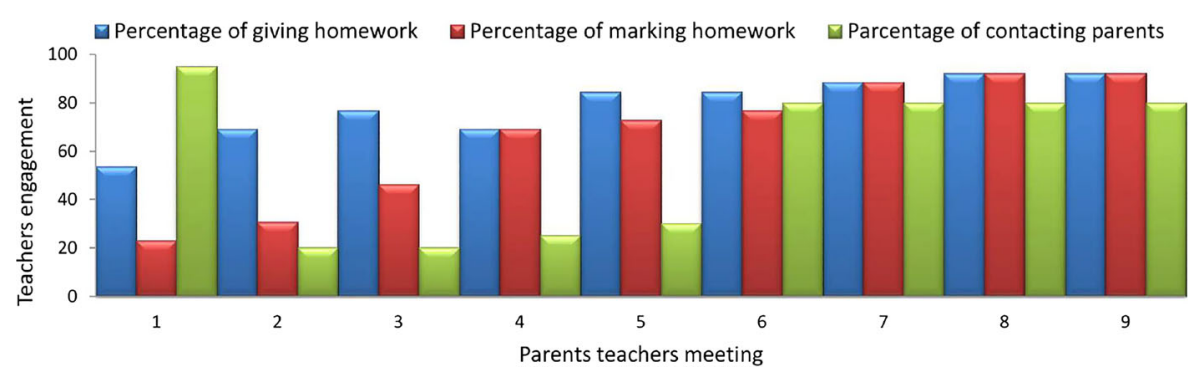

Fig. 3 Teacher engagement for academic year 2019-2020

month as $14,18,20,18,22,23,14$, and 18 respectively. Furthermore the percentage of marking homework rises for each moth as $6,8,12,18,19,20,23,24$, and 18 respectively. Similarly, the percentage of contacting parents ruining as $95 \%, 20 \%$, $20 \%, 25 \%, 30 \%, 80 \%, 80 \%, 80 \%$, and $80 \%$ respectively.

\subsubsection{Parents' perspective}

This section answers the RQ-2, SNS role in parents engagement in children schooling in terms of setting their goals and attending the PTM . In the triangle of learning and engaging (Tanveir et al. 2018), parents have an essential space. The learners' engagement may not be continued without parents' involvement. Parents love their children however, the issues of financial and empowerment engage the parents and the children do not get the priority attention. In the proposed method, it was tried to engage the parents in their children education. Table 4 and Fig. 4 shows the results for parents engagement. In this study, parents were monitored for participation in teachers-parents meetings $(\rho)$, parents who provided WhatsApp $(\omega)$ and parents who took part in WhatsApp discussion $\left(\omega_{D}\right)$. Furthermore, attendance represents the learner guardian attendance, For example, a father visit the school having three kid in the school, so, three classes teachers shows his attendance.

The PTM was held in April, May, August, September, October, November, December, January and February and in this this discussion these meetings are names

Table 4 Parents engagement for the academic year 2019-2020

\begin{tabular}{llll}
\hline Symbol & $\rho$ & $\omega$ & $\omega_{D}$ \\
\hline M1 & 600 & 150 & 0 \\
M2 & 37 & 150 & 0 \\
M3 & 40 & 150 & 0 \\
M4 & 50 & 450 & 0 \\
M5 & 45 & 450 & 0 \\
M6 & 70 & 450 & 0 \\
M7 & 100 & 450 & 198 \\
M8 & 110 & 450 & 277 \\
M9 & 150 & 450 & 300 \\
\hline
\end{tabular}




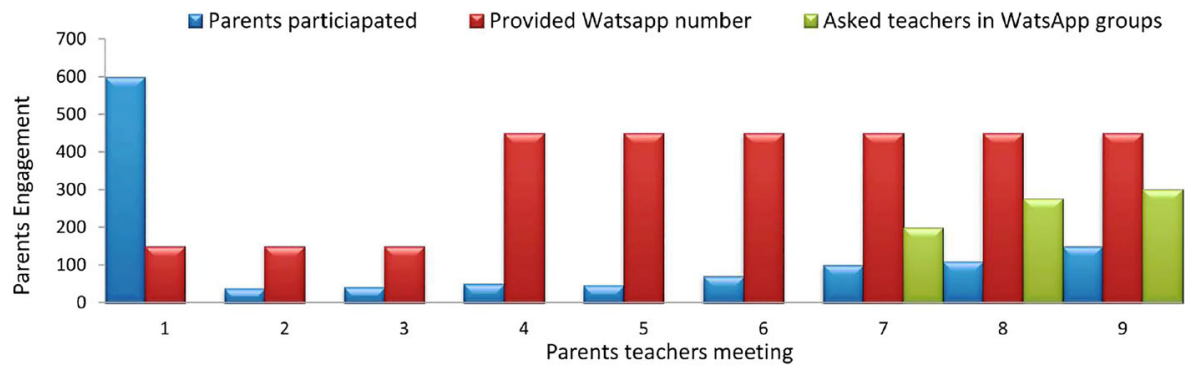

Fig. 4 Parents engagement for the academic year 2019-2020

as M1, M2, M3, M4, M5, M6, M7, M8, and M9 respectively. April has a very high turnout as shown in Table 4. It was the admission month and with the children, it was necessary to sign the admission form and terms by guardians. However, after admission, parents left to visit the school and only $5 \%$ to $6 \%$ came in the next two to three months. Meeting 6 shows a sudden increase as WhatsApp groups were created for direct communication. Additionally, the analysis of meetings 7, 8 and 9 shows that after the Principal has joined the groups, the interaction and involvement of parents increased to $20 \%$. Furthermore, the WhatsApp status shows that these parents also asked about their children who, as usual, did not attend the meetings. The parents participation for overall meeting is $600,37,40,50,45,70,100,110$ and 150 respectively. The first meeting parents shows the parents who visited for admissions. In the January WatsApp discussion among parents and teachers started and in next three months these queries rises from 198 to 300 per section.

\subsubsection{Learners' perspective}

This section answers the RQ-3 and 4, SNS role in motivating and productive engagement of learners to do their homework and minimize truancy. Learners are the main focus of education for whom everything is done. Usually, It is stressful when learners are involved directly, therefore, before learners' involvement, teachers and parents involvement is crucial. The Table 5 and Fig. 5 shows the results. The values in the table are average. They were monitored for the number of students who completed their homework $(\alpha)$, students who partially completed their homework $(\beta)$, and learners attendance for the entire month $(\gamma)$.

The Fig. 6 shows the results of comparing the productivity of learners whose parents attended the PTM and those who did not. The average attendance of learners whose parents attended the meeting increased as 48\%, 58\%, 49\%, 57\%, 59\%, $64 \%, 65 \%, 65 \%$ and $65 \%$ respectively while the learners whose parents did not attend the meeting run as $22 \%, 27 \%, 16 \%, 31 \%, 29 \%, 26 \%, 27 \%, 28 \%$ and $28 \%$ respectively. Furthermore, homework progress whose parents have participated runs as $24 \%, 40 \%, 30 \%, 45 \%, 57 \%, 64 \%, 65 \%, 65 \%$, and $68 \%$ respectively. Similarly, the homework progress whose parents have not participated run as $14 \%, 14 \%$, $11 \%, 15 \%, 21 \%, 21 \%, 21 \%, 21 \%$, and $22 \%$ respectively. Similarly, the passing 
Table 5 Learners engagement for academic year 2019-2020

\begin{tabular}{llll}
\hline Symbol & $\alpha$ & $\beta$ & $\gamma$ \\
\hline M1 & 14 & 170 & 70 \\
M2 & 20 & 250 & 85 \\
M3 & 14 & 198 & 65 \\
M4 & 27 & 240 & 88 \\
M5 & 41 & 270 & 88 \\
M6 & 49 & 260 & 90 \\
M7 & 54 & 230 & 92 \\
M8 & 59 & 200 & 93 \\
M9 & 68 & 160 & 93 \\
\hline
\end{tabular}

percentage of the academic year 2018-2019 and 2019-2020 is follows (as shown in Fig. 7): In academic year 2018-2019 the monthly passing percentage is $23 \%, 25 \%$, $18 \%, 30 \%, 35 \%, 46 \%, 50 \%, 56 \%$, and $60 \%$ respectively, and for the academic year $2019-2020$ is $25 \%, 28 \%, 28 \%, 35 \%, 44 \%, 53 \%, 66 \%, 71 \%$ and $75 \%$ respectively. The academic year 2019-2020, where parents were involved shows a great achievement in results. At the end of the year, $90 \%$ of the complaints registered in the complaint register were about the learners whose parents did not communicate with the teachers.

\section{Discussion}

The underdeveloped countries parents barely support their children for education. Their main preference is to earn for eating and wearing, and remain out for months and years. Due to this intense budgetary stress, children education does not get the main priority. This study is motivated due to the low involvement of parents in their children schooling, resulting in disengagement of learners. This study investigated the use of social media for the relationship between teachers and parents; and the learner engagement on behalf of this digital and fast interactions.

Overall, the results of the SNS (i.e, communication groups on WhatsApp for each section) were promising. In previous years, the maximum percentage of parents participation in the meeting was $5 \%$, as there was no common platform for

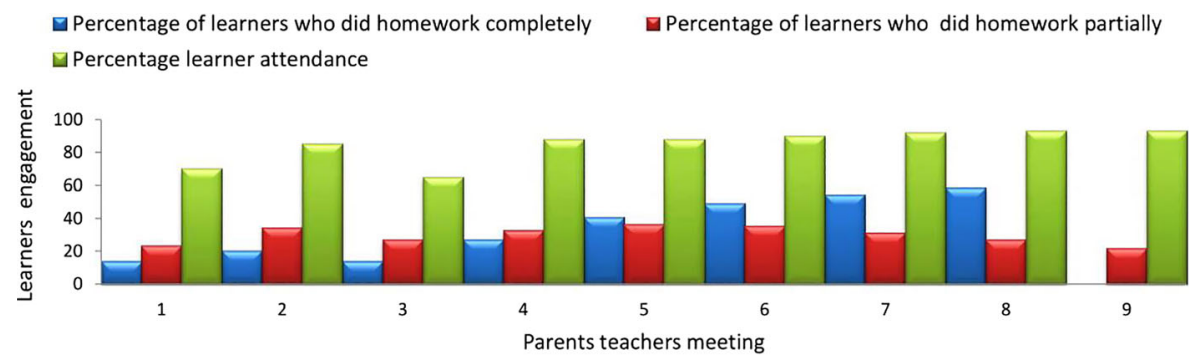

Fig. 5 Learners engagement for academic year 2019-2020 
$\square$ Average attendance whose parents have been communicated $\square$ Homework progress whose parents have participated

Complains whose parents have participated in PTM (\%)
Average attendance whose parents have not communicated u Homework progress whose parents have not participated $\square$ Complains whose parents have not participated in PTM (\%)

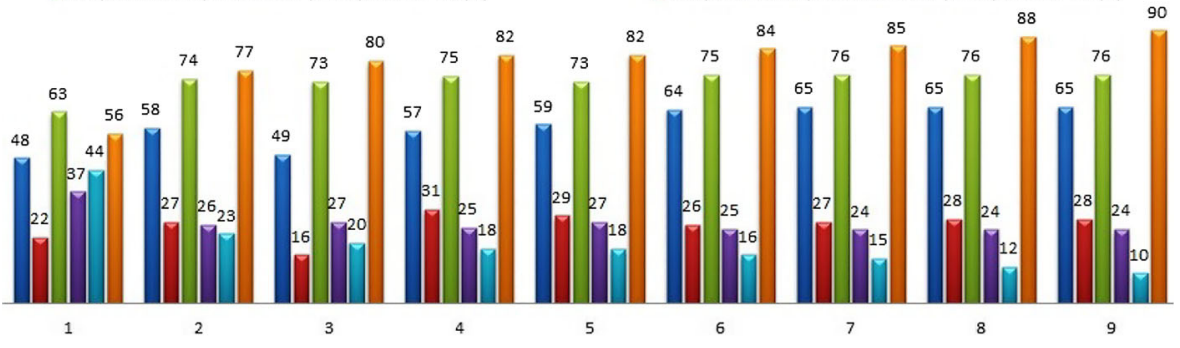

Fig. 6 Learners engagement comparison for the academic year 2019-2020; those (i)whose parents did not participate and (ii) those whose parents participated in PTM

discussion and SNS interaction with parents was rarely used. Interaction with parents and teachers through social media has impressively improved the parents and teachers involvement in children education, resulting productive learners' engagement inside and outside the classroom. The meeting statistics shows (Table 2) that parents attendance in PTM increases from 37 to 150 from first meeting to the last academic meeting; similarly, average 300 queries were entertained on WatsApp for each section per month.

Likewise, teachers involvement with parents and learners has increased. Without WhatsApp groups, such as up to M4 and 2018-2019 statistics, they partially contacted with parents, however, after using WhatsApp and later on when the Principal was added, their contacts with parents increased significantly. Due to queries from parents in social groups, they gave proper time to assign and mark the learners' homework. Statistics shows (Table 3) that homework average frequency increased from 14 to 24 assignments per month and frequency of marking homework increased from 6 to 24 .

The main goal of parents and teachers involvement was to boost learners productivity and creativity. Statistics calculated from this research clearly show that learners whose parents attended the Parents-Teachers Meeting, significantly increased their progress in learning and increased their attendance from $48 \%$ to $65 \%$ rather than learners whose parents were less involved, which slightly change from $22 \%$ to $28 \%$.

Monthly results for the acadam ic year 2018-2019 (Pass percentage)

Monthly results for the acadam ic year 2019-2020 (Pass percentage)

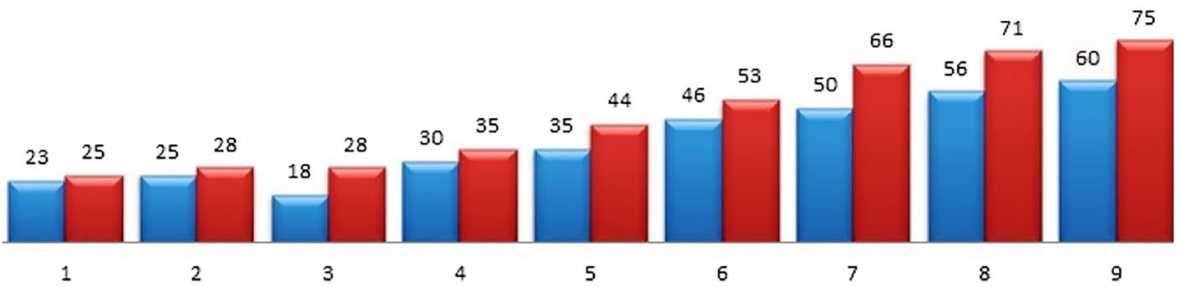

Fig. 7 Learners result comparison for the academic year 2019-2020; those (i)whose parents did not participate and (ii) those whose parents participated in PTM 
Furthermore, this increased their healthy activities and reduced complaints in conduct register. In this case study, complaints decreased from $44 \%$ to $10 \%$ out of total complaints recorded throughout the whole academic year while this ratio for those students whose parents did not attend the PTM increased from 56\% to $90 \%$. Due to attending PTM, the monthly result shows continuously progress, in response to the direct communication of the teachers and the parents, and the long-term result also improved significantly.

It was observed during this study that learners physical hygiene and personal development has improved after parental and teachers involvement. This all aspects leads to better learners' engagement.

\section{Challenges}

The underdeveloped countries go through the critical situation including the financial crisis, social crises and these crises leads to the behavioural issues. The challenges which were faced during this study, can be categorized into three perspectives: i) Technology Itself ii) Parents iii) Teachers

To contact the parents through WhatsApp, smartphones and Internet availability was needed. Considering the financial issues (i.e, most parents are small-scale employees), only $30 \%$ of parents had smartphones. As a result, close relatives or nearby smartphones were used for communication. Second, the majority of parents with smartphones were either completely unable to use social media (i.e. WhatsApp) or had difficulty dealing with them competently owing to illiteracy. Moreover, availability and access to the internet was another issue in the selected area.

During admission, to fill and sign the admission form, we hardly manage to bring the learners/guardian to the school. In hard areas, parents usually do not visit the school and do not ask about their children. Therefore, when they were called to the school by sending school representative to their homes, their first answer was:

It is the task of a teacher to teach children. They are there, why are they calling us to school. We have our work to do and not free to visit the school.

As mentioned earlier, parents illiteracy became hindrance in the way of smooth conducting of this study.

Third, it has been observed that people do not accept changes, especially employees in underdeveloped areas. Teacher is a big barrier for any change in school at first (Tanveir et al. 2018). Consequently, in the first months, the administration faces reluctancy to bring teachers into contact with parents, however, the situation improved later.

\section{Conclusion and future directions}

This study is conducted in the underdeveloped country rural school, Government High School Chapri, District Mianwali, Punjab, Pakistan, to analyse the social media 
impact on parents and teachers to productively engage the learners. The study results are very promising, showing a great increase in all stakeholder involvement.

The recent advances in technology (e.g, Internet of Things (IoT), Artificial Intelligence (AI), 5G, Virtual Reality (VR) and Augmented Reality (AR)), the change in the teaching style and content, our future intent is to deeply investigate the Education Technology (EduTech) for the learners engagement.

\section{Declarations}

Conflict of Interests On behalf of all authors, the corresponding author states that there is no conflict of interest.

\section{References}

Ahmed, M., Dar, M., Tahir, R., Masood, F. (2018). Impact of social media on academic: A quantitative study. In International conference on computing, mathematics and engineering technologies (iCoMET) (pp. 1-1): IEEE. https://doi.org/10.1109/ICOMET.2018.8346373.

Alhazmi, A.K., Rahman, A.A., Zafar, H. (2014). Conceptual model for the academic use of social networking sites from student engagement perspective. In 4 IEEE Conference on e-Learning, e-Management and $e$-Services (IC3e) (pp. 1-1): IEEE. https://doi.org/10.1109/IC3e.2014.7081232.

Aljohani, N.R., Daud, A., Abbasi, R.A., Alowibdi, J.S., Basheri, M., Aslam, M.A. (2019). An integrated framework for course adapted student learning analytics dashboard. Computers in Human Behavior, 92, 679-690.

Badshah, A., Ghani, A., Qureshi, M.A., Shamshirband, S. (2019). Smart security framework for educationalinstitutions using internet of things (iot). Comput. Mater. Contin, 61, 81-101.

Brown, J. (2016). Redefining learning \& teaching using technology. https://www.youtube.com/watch? $\mathrm{v}=A O T E Q V Y D P p g \& l i s t=P L v g n n e w Y 46 I Z$ ZruILsXdhCyuV8QFwQXf\&index $=2 \& \mathrm{t}=0 \mathrm{~s}$.

Daniel, Q. (2017). Longitudinal and contextual associations between teacher-student relationships and student engagement: A systematic review. Review of Educational Research, 87(2), 1-43. https://doi.org/10.3102/0034654316669434.

Daud, A., Aljohani, N.R., Abbasi, R.A., Lytras, M.D., Abbas, F., Alowibdi, J.S. (2017). Predicting student performance using advanced learning analytics. In Proceedings of the 26th international conference on world wide web companion (pp. 415-421).

Davion, J. (2017). The role of teachers in motivating students to learn. Journal of Graduate Studies in Education, 9(1), 46-50.

Dearing, E., Kreider, H., Simpkins, S., Weiss, H.B. (2006). Family involvement in school and low-income children's literacy: Longitudinal associations between and within families. Journal of Educational Psychology, 9(4), 653-664.

Diaz, A., Eisenberg, N., Valiente, C. (2017). Relations of positive and negative expressivity and effortful control to kindergarteners' student-teacher relationship, academic engagement, and externalizing problems at school. Journal of Research in Personality, 67, 3-14. https://doi.org/10.1016/j.jrp.2015. 11.002 .

Goossens, M., Mittelbach, F., Samarin, A. (2012). Parental influences on achievement motivation and student engagement. Boston: Springer.

Hill, N.E., \& Tyson, D.F. (2009). Parental involvement in middle school: A meta-analytic assessment of the strategies that promote achievement. Developmental psychology, 45(3), 740-763. https://doi.org/10. $1037 / \mathrm{a} 0015362$.

Ibanez, M.-B., Di-Serio, A., Delgado-Kloos, C. (2014). Gamification for engaging computer science students in learning activities: A case study. IEEE Transaction on Learning Technologies, 7(3), 291-301.

Javid, I., Amtual, H., Muhammad, A., Naseer, N. (2018). Educational psychology. Allama Iqbal Open University, Islamabd. 
Kangas, M., Siklander, P., Randolph, J., Ruokamo, H. (2017). Teachers' engagement and students' satisfaction with a playful learning environment. Teaching and Teacher Education, 63, 274-284. https://doi.org/10.1016/j.tate.2016.12.018.

Khan, M.M.H., \& Chiang, J.C.L. (2014). Using mobile devices \& social media in supporting engineering education. In IEEE Global Engineering Education Conference (EDUCON) (pp. 1-1).

Kljun, M., Krulec, R., Pucihar, K.C., Solina, F. (2014). Persuasive technologies in m-learning for training professionals: how to keep learners engaged with adaptive triggering. IEEE Transaction on Learning Technologies, 14(8), 1-14.

Laserna, M.S., \& Miguel, M.C. (2018). Social media as a teaching innovation tool for the promotion of interest and motivation in higher education. In 2018 International symposium on computers in education (SIIE) (pp. 1-5). https://doi.org/10.1109/SIIE.2018.8586752.

Lu, Y., Zhang, J., Li, B., Chen, P., Zhuang, Z. (2019). Harnessing commodity wearable devices to capture learner engagement. IEEE Access, 7, 15749-15757. https://doi.org/10.1109/ACCESS.2019.2895874.

Marzo, A., Ardaiz, O., Sanz de Acedo, M.T., Sanz de Acedo, M.L. (2017). Personalizing sample databases with facebook information to increase intrinsic motivation. IEEE Transactions on Education, 60(1), $16-21$.

Mbogho, A.J.W. (2017). Using social media to enhance student engagement. In Emerging Technologies for Education, (Vol. 10676 pp. 320-325).

Nermeen Nokali, H., Bachman, J., Votruba-Drzal, E. (2010). Parent involvement and children's academic and social development in elementary school. Child Development, 81(3), 988-1005.

Popescu, E., \& Leon, F. (2018). Predicting academic performance based on learner traces in a social learning environment. IEEE Access, 6(0), 72774-72785.

Ruiperez-Valiente, J.A., Gaydos, M., Rosenheck, L., Kim, Y.J., Klopfer, E. (2020). Patterns of engagement in an educational massive multiplayer online game: A multidimensional view. IEEE Transactions on Learning Technologies, p. 1-1. https://doi.org/10.1109/TLT.2020.2968234.

Sheldon, S.B., \& Epstein, J.L. (2010). Getting students to school: Using family and community involvement to reduce chronic absenteeism. School Community Journal, 14, 39-56.

Sheldon, S.B., \& Jung, S.B. (2015). The family engagement partnership student outcome evaluation. Johns Hopkins University, School of Education. https://doi.org/10.1007/978-1-4614-2018-7_15.

Silius, K., Tervakari, A.M., Kailanto, M. (2013). Visualizations of user data in a social media enhanced web-based environment in higher education. In IEEE Global Engineering Education Conference (EDUCON) (pp. 1-1).

Tanveer, M.A., Shabbir, M.F., Ammar, M. (2012). Influence of teacher on student' learning motivation in management sciences studies. American Journal of Scientific Research, 67, 76-87.

Tanveir, Z., Amtul, H., Muhammad, A., Naila, N. (2018). Foundation of education. Allama Iqbal Open University, Islamabd.

The National PTA (2000). Building successful partnerships: a guide for developing parent and family involvement programs, national education service.

Waterford.org (2018). How parent involvement leads to student success. https://www.waterford.org/ education/how-parent-involvment-leads-to-student-success/.

Waterford.org (2019). Here's how you can prevent chronic absenteeism and promote school attendance. https://www.waterford.org/education/school-attendance/.

Waterford.org (2020). Water ford report. https://www.waterford.org/education/how-parent-involvment-leadsto-student-success/.

Whitehill, J., San, D., La, J., Serpell, Z., Lin, Y.-C., Foster, A., Movellan, J.R. (2014). The faces of engagement: Automatic recognition of student engagement from facial expressions. IEEE Transactions on Affective Computing, 5(1), 86-98.

Wikipedia (2020a). Socratic method of teaching. https://en.wikipedia.org/wiki/Socratic_method.

Wikipedia (2020b). Montessori method of teaching. https://en.wikipedia.org/wiki/Montessori_education.

Xuesong, Z., Yan, D., Jing, Y. (2018). Investigating learners' technology engagement - a perspective from ubiquitous game-based learning in smart campus. IEEE Access, 6, 10279-10287. https://doi.org/10. 1109/ACCESS.2018.2805758.

Zankadi, H., Hilal, I., Daoudi, N., Idrissi, A. (2018). Facebook and moocs: a comparative analysis for a collaborative learning. In 6th International conference on multimedia computing and systems (ICMCS) (pp. 1-1).

Zhe, Z., \& Ken, H. (2018). Student engagement with teacher and automated feedback on 12 writing. Assessing Writing, 36, 90-102. https://doi.org/10.1016/j.asw.2018.02.004. 
Publisher's note Springer Nature remains neutral with regard to jurisdictional claims in published maps and institutional affiliations.

\title{
Affiliations
}

\section{Afzal Badshah ${ }^{1}$ (1) - Ateeqa Jalal ${ }^{2}$. Ghani Ur Rehman ${ }^{3}$ (I) . Muhammad Zubair ${ }^{3}$ (D) Muhammad Muneer Umar ${ }^{4}$}

\author{
Afzal Badshah \\ afzal.phdcs120@iiu.edu.pk \\ Ateeqa Jalal \\ ateeqajalal@gmail.com \\ Muhammad Zubair \\ m.zubairpaf@gmail.com \\ Muhammad Muneer Umar \\ muneer.umar@kust.edu.pk \\ 1 Department of Computer Science and Software Engineering, International Islamic University, \\ Islamabad, 44000, Pakistan \\ 2 Department of Computer Science, University of Science \& Technology, Bannu, Pakistan \\ 3 Department of Computer Science and Bioinformatics, Khushal Khan Khattak University, \\ Karak, 27000, Pakistan \\ 4 Institute of Computing, Kohat University of Science and Technology, Kohat, Pakistan
}

